\title{
Imidazole Compounds Accumulated by Purine Mutants of Neurospora crassa
}

\author{
BY H. BERNSTEIN \\ Kerckhoff Laboratory of Biology, \\ California Institute of Technology, Pasadena, California, U.S.A.
}

(Received 4 October 1960)

\begin{abstract}
SUMMARY
A procedure is given for the detection of imidazole compounds accumulated in the mycelium of adenine mutants of Neurospora crassa. Of five such compounds detected, four have been tentatively identified. The distribution of these imidazoles among the mutants investigated allows a correlation between the adenine loci and the steps of purine biosynthesis.
\end{abstract}

\section{INTRODUCTION}

Extensive enzymic studies with avian liver systems have led to the elucidation of the complete pathway of adenosine- $5^{\prime}$-monophosphate biosynthesis (Buchanan, 1958-59). The seven reaction steps following imidazole ring closure are shown in Fig. 1. From studies of the corresponding reaction pathway in Neurospora crassa, Giles, Partridge \& Nelson (1957) have presented evidence that E mutants (Table 1) are blocked in the conversion of inosinic acid to adenylosuccinic acid ribotide. F mutants

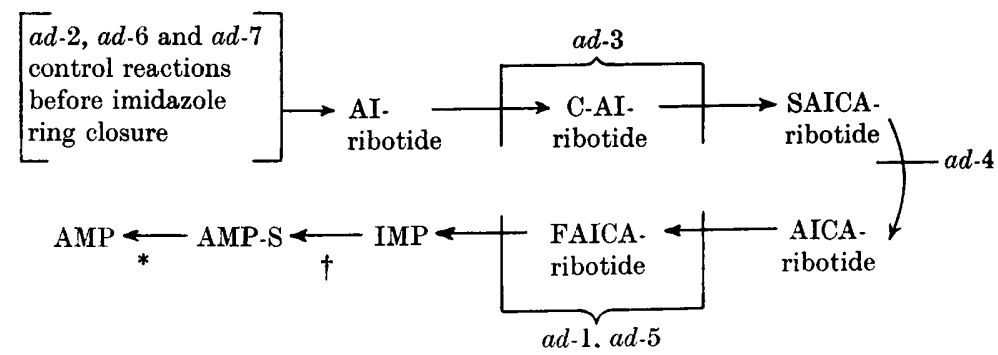

Fig. 1. Steps in purine biosynthesis controlled by adenine loci as judged from imidazole accumulation by mutants of Neurospora crassa.

Key: AMP, adenosine-5' -phosphate; AMP-S, adenylosuccinic acid ribotide; IMP, inosinic acid; FAICA-ribotide, 5-formamido-4-imidazolecarboxamide ribotide; AICAribotide, 5-amino-4-imidazolecarboxamide ribotide; SAICA-ribotide, 5-amino-4-imidazole- $N$-succinocarboxamide ribotide; CAI-ribotide, 5-amino-4-imidazolecarboxylic acid ribotide; AI-ribotide, 5-amino-imidazole ribotide.

* Giles et al. (1957) have shown that mutants at the ad-4 locus are deficient in a de-acylase which splits both SAICA-ribotide and AMP-S.

$\dagger a d-8$ mutants were shown also by Giles et al. (1957) to be blocked in the conversion of IMP to AMP-S.

and mutant 44206 were also shown to lack activity for a bifunctional enzyme which catalysed the de-acylation of 5 -amino-4-imidazole- $N$-succinocarboxamide ribotide and adenylosuccinic acid ribotide to 5-amino-4-imidazolecarboxamide ribotide 
and adenosine-5' $\mathbf{5}^{\prime}$-phosphate, respectively. Dr T. French is reported (Buchanan, 1958-59) to have found in wild-type $N$. crassa all the purine biosynthetic enzymes present in the avian liver system. In the present work mutants representing several adenine loci of $N$. crassa were studied for their ability to accumulate imidazole compounds, intermediate in purine biosynthesis. All adenine mutants found to date have been allocated to eight loci (Barratt, Newmeyer, Perkins \& Garnjobst, 1954; Giles et al. 1957); these are summarized in Table 1.

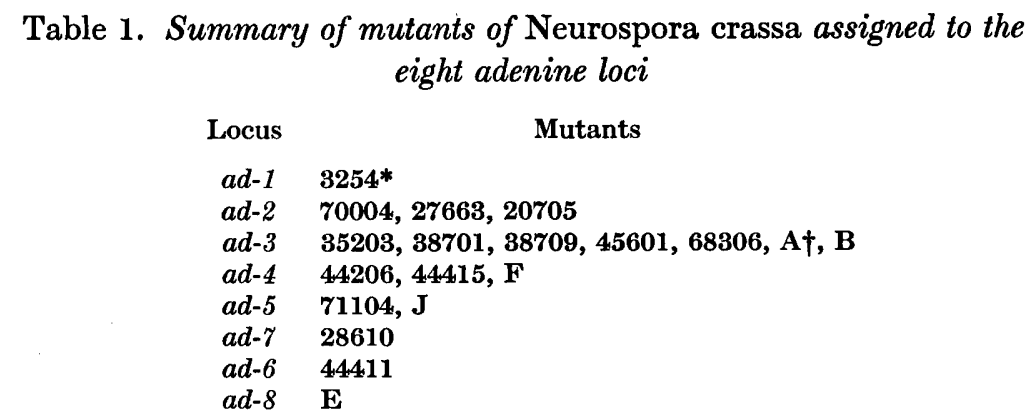

* Mutants with numerical designations came from the early mutant searches of Beadle \& Tatum (1945).

$\dagger$ Letter designations were given by Giles et al. (1957) to groups of mutants related by heterokaryon complementation tests.

\section{METHODS \\ Extraction of mycelia}

The cultures of Neurospora crassa used as stocks, or as a source of conidial inocula, were grown in test tubes containing a complete medium described by Horowitz (1947). To obtain large quantities of mycelium, mutants were grown in carboys containing $10 \mathrm{l}$. of minimal medium (Beadle \& Tatum, 1945) supplemented with limiting amounts of adenine sulphate (usually $30 \mu \mathrm{g} . / \mathrm{ml}$.). All mutants were grown at $25^{\circ}$, except the temperature sensitive strains $(44206,44415,70004)$ which were grown at $\mathbf{3 5}^{\circ}$. After 3-4 days of growth under forced aeration the mycelia were harvested by pouring the contents of the carboys through cheesecloth. The mycelial mats were placed in a Waring Blender and boiling water was added (about 11 .) $100 \mathrm{~g}$. wet mycelium). After disintegration the extracts were filtered through Whatman no. 1 filter paper on a Buchner funnel. The filtrates were then lyophilized overnight, leaving thick syrupy extracts in the flasks. Five to $10 \mathrm{ml}$. of water were sufficient to take up the extract from $100 \mathrm{~g}$. mycelium. Residual material were separated by centrifugation and washed several times with $1 \mathrm{ml}$. portions of water which were added to the soluble fraction. The solutions contained all the imidazoles. The residues were discarded.

\section{Detection of accumulated imidazoles}

The redissolved extracts were spotted directly, or with dilution, on Whatman no. 1 paper and resolved by ascending chromatography in a variety of solvents. Isopropanol, water, and conc. aqueous $\mathrm{NH}_{4} \mathrm{OH}$ (sp. gr. $0 \cdot 880$ ) in the volume ratios $70: 20: 10$ and 70:40:10 were the most useful systems. After drying, the chromatograms were sprayed very lightly with diazosulphonic acid reagent (Ames \& Mitchell, 
1952), and again very lightly with $5 \%(w / v)$ aqueous $\mathrm{Na}_{2} \mathrm{CO}_{3}$ solution. By this procedure five distinct imidazole compounds not present in wild-type mycelium were detected in extracts from the mycelia of the mutant strains.

\section{Isolation of Compounds I and II (Table 3)}

To $14 \mathrm{ml}$. of the water soluble extract of $135 \mathrm{~g}$. wet weight of mutant 44206 mycelium (see Methods) an equal volume of methanol was added. A precipitate was formed which was washed with $50 \%(\mathrm{w} / \mathrm{v})$ methanol in water. The soluble fractions, containing virtually all of Compounds I and II, were combined to a total volume of $23.5 \mathrm{ml}$.

A Dowex exchange resin (1-X2, 200-400 mesh), from which the fines had been removed by repeated washings, was equilibrated with $2 \mathrm{M}$-formic acid. This was placed in a column $2.2 \mathrm{~cm}$. in diam. to a volume of $170 \mathrm{~cm} .{ }^{3}$. Water at $3.5^{\circ}$ was circulated through a jacket which surrounded the column. The flow rate of solvent was kept at about one drop every 15 sec. by maintaining the system under controlled positive pressure. A mixing vessel of $125 \mathrm{ml}$. capacity was included in the system to allow gradient elution according to the procedure of Thompson (1955). The column was first washed with distilled water and then the sample was added. For elution, the series of solutions listed in Table 2 were used in the order given. Successive solutions were added only after the $\mathrm{pH}$ value of eluted fractions did not change measurably. By using an automatic fraction collector, 5-10 ml. portions were collected. Compound II began to elute at $\mathrm{pH} 1.9$ (solution 7); it came off the column in a total volume of $273 \mathrm{ml}$. After an additional $135 \mathrm{ml}$. of eluent had passed through, compound I began to appear and came through in the next $82 \mathrm{ml}$.

Table 2. Solutions used for the serial elution of chromatographic columns

\begin{tabular}{|c|c|c|c|c|}
\hline No. & Solution & $\begin{array}{c}\text { Molarity } \\
\text { of } \\
\mathrm{NH}_{4}^{+}\end{array}$ & $\begin{array}{c}\text { Molarity } \\
\text { of } \\
\text { anion }\end{array}$ & $\begin{array}{c}\text { Measured } \\
\text { pH } \\
\text { value }\end{array}$ \\
\hline $\mathbf{1}$ & Distilled water & • & . & - \\
\hline 2 & Ammonium acetate buffer & $0 \cdot 4$ & $1 \cdot 2$ & $4 \cdot 28$ \\
\hline 3 & Ammonium acetate buffer & $0 \cdot 4$ & $1 \cdot 0$ & $4 \cdot 40$ \\
\hline 4 & Ammonium formate buffer & $0 \cdot 4$ & $1 \cdot 1$ & $3 \cdot 28$ \\
\hline 5 & Acetic acid & . & $1 \cdot 0$ & $2 \cdot 53$ \\
\hline 6 & Formic acid & . & $1 \cdot 0$ & 1.97 \\
\hline 7 & Formic acid & - & $6 \cdot 0$ & $1 \cdot 17$ \\
\hline
\end{tabular}

\section{Separation of Compounds III and IV (Table 3)}

An extract of mutant 45601 containing both Compounds III and IV was subjected to a chromatographic procedure similar to that described above. Compound III was eluted by water very close to the front, and Compound IV came off soon after. Though separation was achieved, both fractions were impure. However, they were satisfactory for chromatographic comparisons.

\section{Abbreviations}

The following abbreviations, modified from Buchanan (1958-59), are used: AMP, adenosine-5' -phosphate; AMP-S, adenylosuccinic acid ribotide; IMP, inosinic 
acid; FAICA-ribotide, 5-formamido-4-imidazolecarboxamide ribotide; AICA-ribotide, 5-amino-4-imidazolecarboxamide ribotide; SAICA-ribotide, 5-amino-4-imidazole- $\boldsymbol{N}$-succinocarboxamide ribotide; CAI-ribotide, 5 -amino-4-imidazolecarboxylic acid ribotide; AI-ribotide, 5-amino-imidazole ribotide.

\section{RESULTS}

The colour reactions and distribution of the five detected imidazoles among the mutants are detailed in Tables 3 and 4.

Table 3. Colour reactions of accumulated compounds

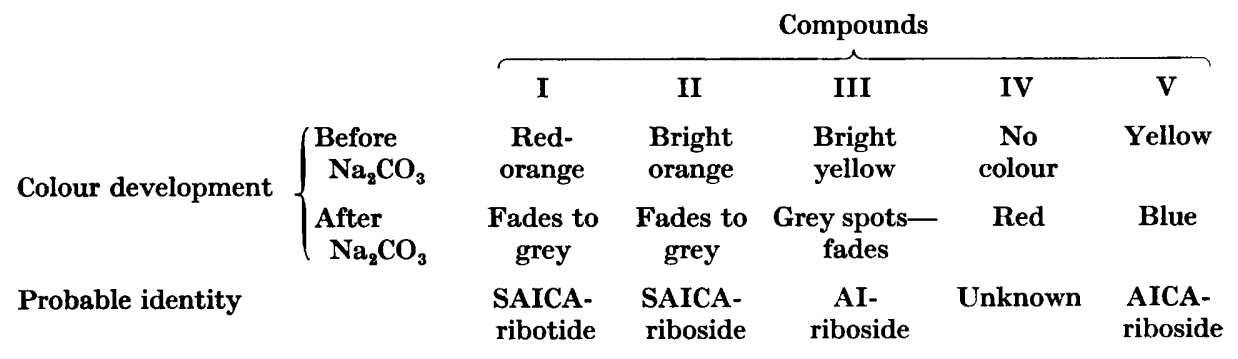

Table 4. Distribution of accumulated imidazoles

\begin{tabular}{|c|c|c|c|c|c|c|}
\hline \multirow[b]{2}{*}{ Locus } & \multirow[b]{2}{*}{ Mutants } & \multicolumn{5}{|c|}{ Compounds } \\
\hline & & I & II & III & IV & $\mathbf{v}$ \\
\hline$a d-1$ & 3254 & - & + & - & - & + \\
\hline \multirow[t]{3}{*}{$a d-2$} & 70004 & - & - & - & - & - \\
\hline & 27663 & - & - & - & - & - \\
\hline & 20705 & - & - & - & - & - \\
\hline \multirow[t]{4}{*}{$a d-3$} & 35203 & - & - & + & + & - \\
\hline & 38701 & - & - & + & + & - \\
\hline & 38709 & - & - & + & + & - \\
\hline & 45601 & - & - & + & + & - \\
\hline$a d-4$ & 44206 & + & + & - & \pm & - \\
\hline$a d-5$ & 71104 & - & + & - & \pm & + \\
\hline$a d-6$ & 28610 & - & - & - & - & - \\
\hline$a d-7$ & 444111 & - & - & - & - & \\
\hline
\end{tabular}

The following designations were used: + , compound present in mycelial extract; \pm , compound present, but in low concentration; - , compound not detected.

\section{Characterization}

Compound I at $\mathrm{pH} 7$ had an ultraviolet absorption peak at $269 \mathrm{~m} \mu$. By the method of Mejbaum (1939) it was shown to contain a pentose moiety. A sample of SAICA-ribotide generously provided by Dr T. French proved to be identical with Compound I, both in colour development and chromatographic mobility. When Compound I and the known SAICA-ribotide were hydrolysed by alkaline phosphatase each formed a product identical on chromatograms with Compound II.

Compound II at pH 7 absorbed maximally at $268 \mathrm{~m} \mu$, and was also shown to contain a pentose moiety. By using the procedure of Allen (1940) it was proved to lack a phosphate group. On hydrolysis at $105^{\circ}$ with conc. $\mathrm{HCl}$, for $15 \mathrm{hr}$. in a sealed 
tube, Compound II yielded aspartic acid and glycine. The presence of aspartic acid on hydrolysis, the shape of the ultraviolet absorption curve, and position of the absorption maximum compared well with the properties reported for SAICAribotide (Gots \& Gollub, 1957; Lukens \& Buchanan, 1959 a). The phosphate determination and the data from hydrolysis with alkaline phosphatase further showed that Compound II was SAICA-riboside.

Compound III formed an orange-red Bratton-Marshall reaction product (Bratton \& Marshall, 1939) which absorbed maximally at 500-502 $\mathrm{m} \mu$. No absorption maximum in the ultraviolet region was detected. That Compound III failed to bind to an anion exchange resin argues against the presence of carboxyl or phosphate group. The Bratton-Marshall product of AI-ribotide is reported to be salmon-orange and to absorb maximally at $500 \mathrm{~m} \mu$ (Lukens \& Buchanan, 1959 b). Also this compound is reported to have no ultraviolet absorption maximum above $210 \mathrm{~m} \mu$. All the properties observed for Compound III are consistent with its being AI-riboside.

The Bratton-Marshall reaction product of Compound IV was orange-red and absorbed maximally at 534-538 $\mathrm{m} \mu$. This corresponds to none of the maxima reported for the imidazoles involved in purine biosynthesis. However, since the concentration of this compound appeared to decrease as more care was taken in preparation of extracts, it seems likely that Compound IV was a reaction product of Compound III.

Ames \& Mitchell (1952) reported that, of 16 compounds tested by their diazotization procedure, only 5-amino-4-imidazolecarboxamide (AICA) gave a blue reaction product. Subsequently AICA-ribotide was observed by the present author to give this blue colour. Compound $\mathrm{V}$ gave a colour reaction identical with that of the aglycone and AICA-ribotide. Chromatographic evidence suggested that Compound $\mathrm{V}$ was either AICA or AICA-riboside.

\section{DISCUSSION}

Knowing the distribution and probable identity of the detected imidazole compounds it is possible to correlate the adenine loci and the steps of purine biosynthesis (Fig. 1). Since $a d-2, a d-6$ and $a d-7$ mutants of Neurospora crassa can use IMP or hypoxanthine in place of adenine as a growth supplement (Mitchell \& Houlahan, 1946) and yet accumulate no imidazole compounds, they can be assigned to steps preceding imidazole ring closure. This conclusion is in accord with an observation of Mitchell \& Houlahan (1946). All ad-3 mutants accumulate a distinctive purple pigment in their growth media. The purple pigment, which seems to have associated with it a $305 \mathrm{~m} \mu$ ultraviolet absorption maximum, is probably a reaction product of Compound III. It was also shown by these authors that the double mutants of 35203 ( $a d-3$ ) in conjunction with $a d-2, a d-6$ and $a d-7$ mutants, accumulate no purple pigment. The double mutant 35203, $44206(a d-4)$ does accumulate the pigment. This again places the $a d-2, a d-6$ and $a d-7$ block before, and the $a d-4$ block after, the reaction controlled by ad-3.

Colourless solutions of SAICA-riboside (Compound II) will turn red in time, especially at low $\mathrm{pH}$ values or on exposure to air. The reddish appearance of mutant $44206(a d-4)$ mycelia is probably due to this effect. The percentage yield of SAICAriboside and SAICA-ribotide in the dried mycelia of mutant 44026 can be calculated 
from the observed optical densities at the ultraviolet absorption maxima and the extinction coefficient given by Lukens \& Buchanan (1959a). The yields of the riboside and ribotide were found to be $2 \cdot 1$ and $0.023 \%$, respectively, of the dry weight of its mycelia.

The two intermediates CAI-ribotide and FAICA-ribotide and the corresponding ribosides, known to be the least stable of the imidazoles, were not detected in any extracts.

The author wishes to thank Drs H. K. Mitchell and A. Miller for their interest and constructive criticism throughout the course of this investigation. This work was supported in part by the Arthur MacCallum Foundation and by a National Science Foundation Grant (G 3438).

\section{REFERENCES}

Aluen, R. J. L. (1940). The estimation of phosphorus. Biochem. J. 34, 858.

Ames, B. N. \& Mrtchell, H. K. (1952). The chromatography of imidazoles. J. Amer. chem. Soc. 74, 252.

Barratt, R. W., Newmeyer, D., Perkins, D. D. \& Garnjobst, L. (1954). Map construction in Neurospora crassa. Advanc. Genet. 6, 1.

Beadle, G. W. \& Tatum, E. L. (1945). Neurospora II. Methods of producing and detecting mutations concerned with nutritional requirements. Amer. J. Bot. 32, 678.

Bratton, A. C. \& Marshall, E. K. (1939). A new coupling component for sulfanilamide determination. J. biol. Chem. 128, 537.

Buchanan, J. M. (1958-59). The enzymatic synthesis of purine nucleotides. Harvey Lect. $54,104$.

Giles, N. H., Partridge, C. W. H. \& Nelson, N. J. (1957). The genetic control of adenylosuccinase in Neurospora crassa. Proc. nat. Acad. Sci., Wash. 43, 305.

Gots, J. S. \& Gollub, E. G. (1957). Sequential blockade in adenine biosynthesis by genetic loss of an apparent bifunctional deacylase. Proc. nat. Acad.Sci., Wash. 43, 826.

Horowitz, N. H. (1947). Methionine synthesis in Neurospora. The isolation of cystathionine. J. biol. Chem. 171, 255.

Lukens, L. N. \& Buchanan, J. M. (1959a). Biosynthesis of the purines. XXIII. The enzymatic synthesis of $N$-(5-amino-1-ribosyl-4-imidazolecarbonyl)-L-aspartic acid 5'-phosphate. J. biol. Chem. 234, 1791.

Lukens, L. N. \& Buchanan, J. M. (1959b). Biosynthesis of purines. XXIV. The enzymatic synthesis of 5-amino-1-ribosyl-4-imidazolecarboxylic acid 5'-phosphate from 5-amino-1-ribosylimidazole 5-phosphate and carbon dioxide. J. biol. Chem. 234, 1799.

Mejbaum, W. (1939). Über die Bestimmung kleiner Pentosemengen, inbesondere in Derivaten der Adenylsäure. Z. physiol. Chem. 258, 117.

Mrtchell, H. K. \& Houlahan, M. B. (1946). Adenine requiring mutants of Neurospora crassa. Fed. Proc. 5, 370.

Thompson, A. R. (1955). Amino acid sequence in lysozyme; 2. Elution chromatography of peptides on ion-exchange resins. Biochem. J. 61, 253. 